Vol. XXIII No 1

\title{
NEW APPROACH - QUADRANGLE OF KNOWLEDGE BASED SUSTAINABILITY
}

\author{
Ovidiu NICOLESCU*, Ciprian NICOLESCU** \\ * Romanian Scientific Management Society, Bucharest, Romania \\ ** The Bucharest University of Economic Studies, Romania \\ ciprian.nicolescu@gmail.com
}

\begin{abstract}
In our paper we start the analysis of the performance in the knowledge based economy from two premises: a. The productivity of the new economy is much higher comparative with the previous economic systems; $b$. There are at least six factors which determine the deep change of knowledge business organisation performances. Based on this approach we mention several specific ways for the evaluation of the knowledge based performances formulated by certain renowned international specialists. Finally, we elaborate a new concept regarding the approach and evaluation of the performance in the knowledge based economy - quadrangle of sustainability based on knowledge.
\end{abstract}

\section{Keywords: knowledge, sustainability, quadrangle, efficiency, effectiveness}

\section{Introduction}

The central question of any economic entity is getting a sustainable performance. Therefore in addressing knowledge-based economy and its main component knowledge-based organization, pointing out elements on the performance it is essential. The analysis that we have undertaken and the studies carried out by some specialists as [1], [2], [3], [4], [6], [7], [8], [9], [10], [11], have revealed that the economy based on knowledge generates superior performance compared to previous economic systems.

There are multiple explanations, among them we briefly present the following two:

a) The productivity of knowledge, the main component of intellectual capital increases to incredible levels, especially due to its dematerialisation and demultiplication, that make possible to use the same knowledge, concomitant by a large number of people and/ or organizations that are in different areas, which may be located at thousands of miles distant. For example, a system for selling airplane tickets, or a software for accounting of firm can be used simultaneously by tens, hundreds, thousands, tens of thousands, hundreds of thousands or even millions of persons and/ or organizations. As a result, the cost per user decreases greatly, almost in the same proportion with the number of users, and outputs/ revenues generated and/ or facilitated are multiply in similar proportions.

b) The degree of potentiating, using and capitalizing of other forms of classical capital - technical material, financial and human - are amplified very much because:

- the capacity and quality of the tools, equipments, buildings, etc., due to the incorporation of new knowledge more sophisticated and more productive, increase very much, which determine realizing of better and more products and services and thus achieving higher added value and incomes;

- the same money can create, use and disseminate greater quantities of 
knowledge and thus generate additional revenues;

- people that constitute the human resources, in terms of the knowledge society, possess a greater volume of knowledge and consequently a higher capacity of their processing, have a faster access to a immense amount of knowledge of high quality, can interconnect and collaborate more easily with many other people and organizations, regardless of the distance, become more creative generating valuable knowledge, use and exploit at higher level own knowledge and knowledge of organizations were they are integrated. All these determine substantially higher individual and organizational productivities, reflected at the macro social level in amplification of GDP, national budgets and the living standards of the population.

Increasing labour productivity to levels unprecedented is the main source of high performance of knowledge based organization.

\section{Factors that substantially modify performances of knowledge based organizations}

To deepen aspects on performances of modern social and economic entities is very useful to identify new factors that influence their effectiveness and efficiency. These have a significantly different content, determined by partial, but essential changing of inputs - with the location in forefront of knowledge - by changes within economic, human, technical and managerial mechanisms and major changes, regarding to the structure and functionality, of economy and society based on knowledge. As a result, the outputs of economic and social entities are partly different.

After analysis we have carried out, we identified six specific factors that determine significant changes in performances of knowledge based entities. See figure 1 .

Without a doubt, the vast amount of knowledge used in organizations represents the first factor of influence. In the knowledge-based entity they are:

- an essential resource of organizations;

- a basic raw material;

- a major factor of production;

- an essential component of intellectual capital;

- a product itself and/ or major attributes of other products;

- the most important generator of competitive advantage in micro, mezzo, macro and international organizations.

So far no other participant element at economic processes from an organization hadn't a palette so comprehensive of functions and an impact so intense and extended on other resources and activities, on performance, as have the knowledge.

A second specification required, is the fact that part of knowledge, often the most important, represented by tacit knowledge, can't be quantified, or can be gauged only partially and indirectly. So, both part of knowledge inputs and part of knowledge outputs, are not measurable in economic terms. Hence, the great difficulty of determining efficiency and the need to resort to new approaches likely to provide a reasonable estimate of its, essential for sustainable development of economic and social entity. Obviously, all the elements mentioned influence in a great extent and the approach way of effectiveness. However, because the organization's efficacy is determined by comparing achievements, to the initial provisions of objectives and work processes, a relatively low part is quantified and the impact is lower, compared to the one referring to efficiency. 


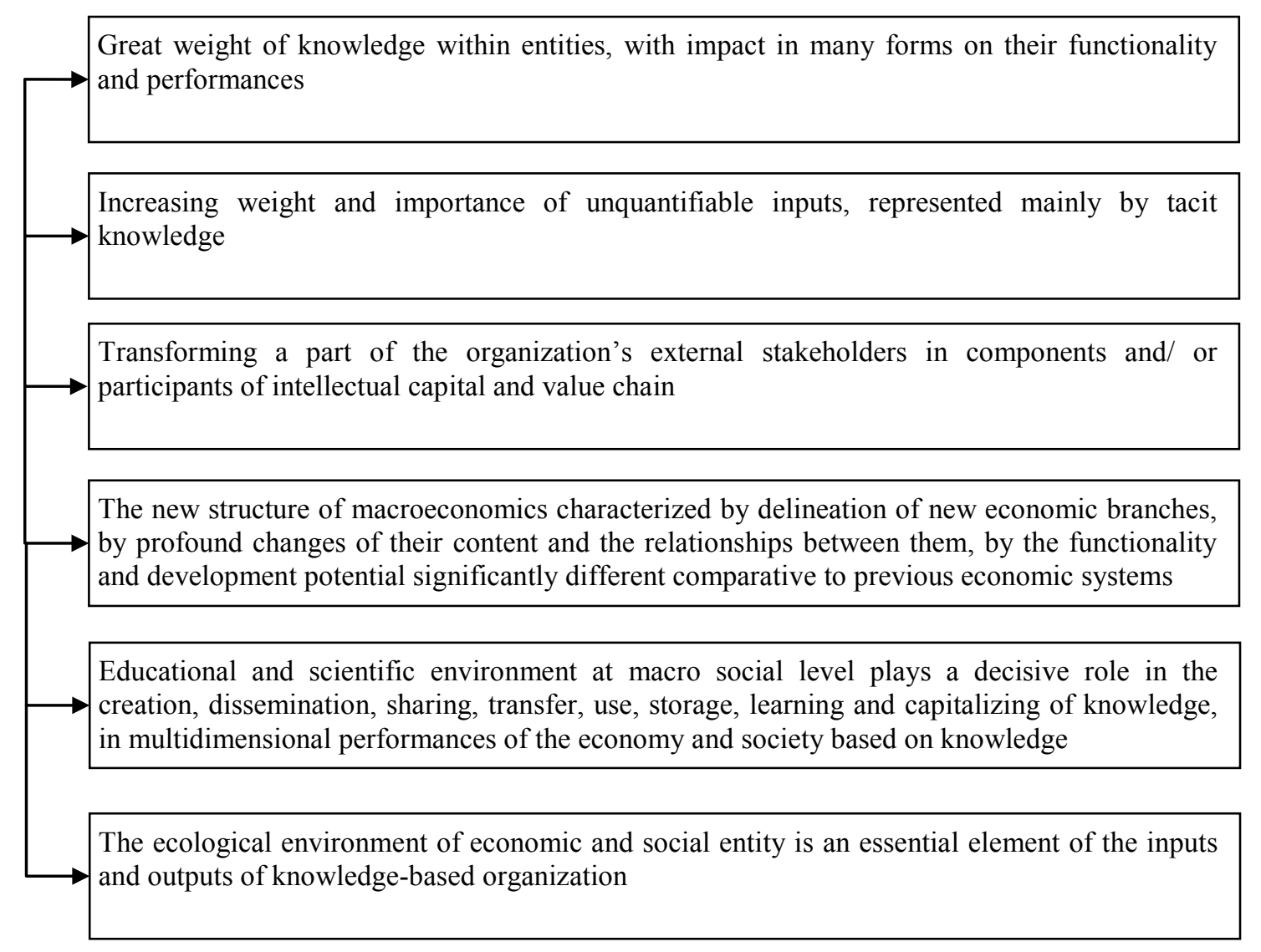

Figure 1: The main factors that determine the essential change of the effectiveness and efficiency within knowledge based organizations

A third element of specificity resides in coverage sphere of efficiency and effectiveness. In socio-economic entities based on knowledge, intellectual capital and value chain far outweigh the classic borders of organization, incorporating not a few elements from external environment. Much of the organization's external stakeholders, become component or are directly and significant involved in its economic, managerial, human and/ or technical mechanisms. As such, when forecasting, determining and evaluating the effectiveness and efficiency of the entity based on knowledge, the elements referring to stakeholders must not and can't miss. Omission of them from gnosiological point of view is an error, and from the pragmatic point of view represents a major shortcoming that, if it persists for a longer period, threatening the very existence of the organization.

The following three factors are likely macro social, referring to essential changes in the overall structure of the economy and its main components. Undoubtedly, the most important change of component refers to education and scientific research that become productive branches with the greatest impact on the functionality and performance at all levels - micro, mezzo, macro and international.

Transformation of ecological environment in an essential factor of effectiveness and efficiency of economic and social entities sixth factor considered - is based on the following aspects:

- some of environmental elements (water, air, soil, gases, etc.) are inputs within organizations, their characteristics reflecting in costs;

- prevention of pollution and environmental protection by organizations, require expenses incurred by them, some of this organizations spending a lot of money; 
- part of organizations outputs influence in a way or another the ecological environment, and this influence is an intrinsic component, though not always measurable, of effectiveness and efficiency of the organization.

\section{Quadrangle of knowledge based sustainability}

Examining the content of the six factors, result and the need for a systemic approach, from a long term sustainable perspective of knowledge based organization performances.

Based on the triangle of sustainability elaborated by Zollinger [6], respectively Nicolescu [5], we have conceived a new approach synthesized in the form of quadrangle of knowledge based sustainability, viewed in figure 2 .

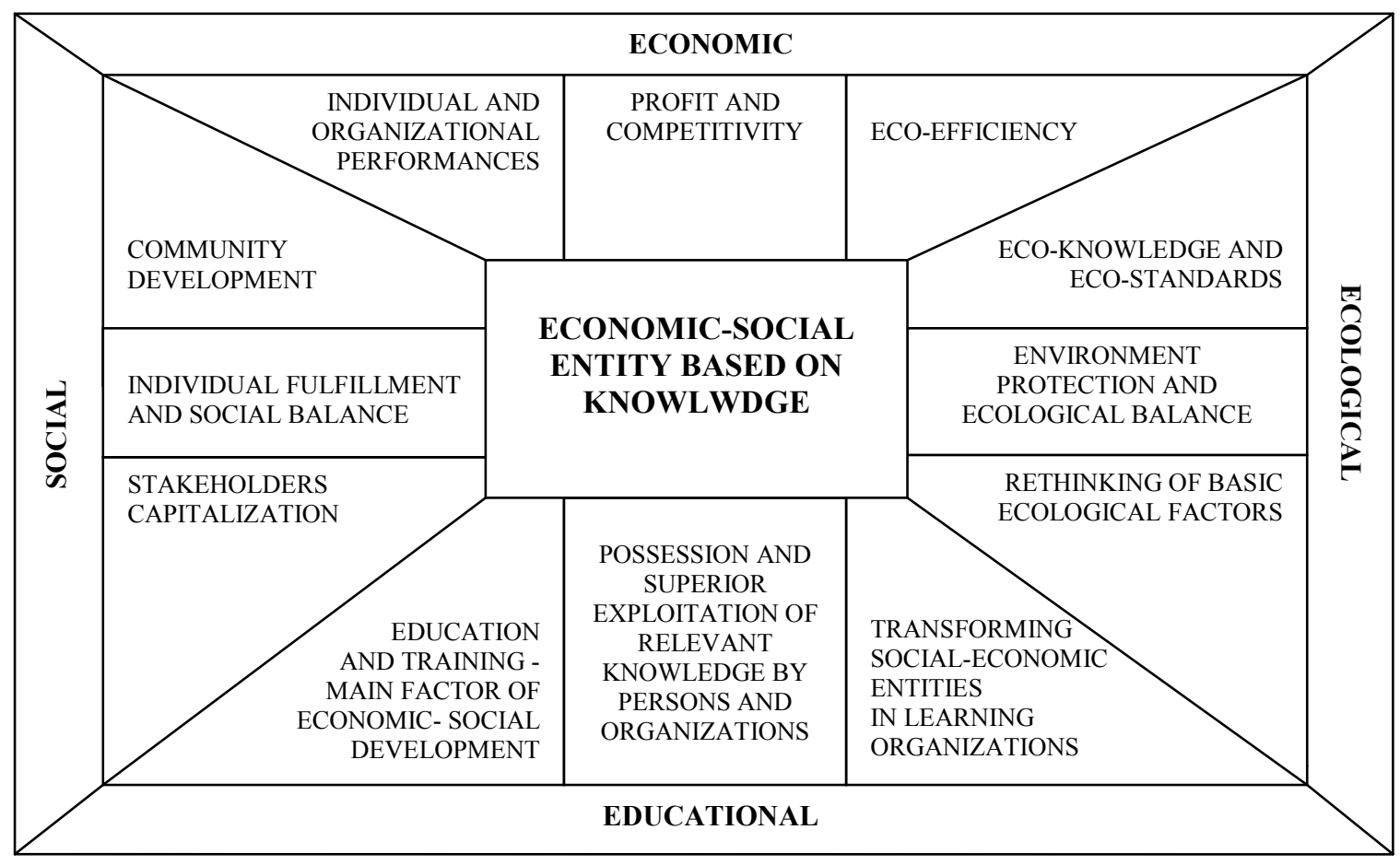

Figure 2: Quadrangle of knowledge based sustainability

Quadrangle of sustainability based on knowledge - as the name suggests - it is quadrodimensional and takes into account modern economic entities:

a) Economic dimension that places in foreground three major aspects:

- Competitiveness that has as main support obtaining of profit. An organization if does not get profit, hasn't enough resources for development and therefore can't survive long-term. Therefore getting continuously profit is essential for any economic entity;

- Realization of individual and organizational performances, that are interrelated. In conditions of knowledge based entities individual performances of each component of the organization are more important due to extremely high productivity of knowledge. Consequently the contribution of each component of the organization, of each specialist based on knowledge - positive or negative - has a significantly higher impact on the overall performances of the organization. The second facet considered envisages organizational performances, of the entity as a whole, in fact the most important in terms of sustainability. Of course, organizational performances are based on individual performances, but which by interacting in an intelligent approach based on 
competitive strategic vision generate economic synergy;

- Eco - efficiency, reflect both economic and ecological effects, marking and on this plan change the content of efficiency in the knowledge based organization. Eco-efficiency is a new concept, that points that approach of elements regarding to costs and revenues, inputs and outputs, must not be limited only to economic ones, but to consider and the environmental ones, not less important than the first.

b) Social dimension focuses on the following aspects:

- Individual fulfilment of the components of the entity, with a major impact on the degree of motivation and capacity to treat well knowledge, on the loyalty to the organization and other colleagues. Individual fulfilment has so not only a personal dimension, but falls upon the integration in organization and effective contribution to the achievement of its objectives. Individual fulfilling is approached in an integrative vision, in terms of ensuring the balance at all levels - organizational, community, regional and national;

- Capitalization of stakeholders envisages the essentially mutation produced in knowledge based organization, namely that the functionality and performances depend not only by managers and executives but also, in increasingly extent, by customers, suppliers, intermediaries, financiers, consultants, trainers, etc. Valorisation of all major stakeholders tends to be conditioned not only to obtain high performance, but also for the survival of the organization.

- Community development highlights multiple and intense relations of interdependencies within each knowledge based entity and social economic community in which it manifest. Because many of entity's inputs - human, knowledge, technical material, information, and even financial - coming from involved community, is the interest of the entity to its development, in order to provide inputs of superior quality and to be more responsive and friendly with entity's outputs - goods, services, knowledge.

c) Environmental dimension of performances, recently shaped for the organizations, is structured on three levels:

- Ensuring environmental protection so as to prevent polluting phenomena which were very numerous in the last century and a half. Simultaneously it aims to ensuring ecological balance which often requires not only decisions and preventive actions, but also corrections. Ecological balance across all systems local, regional, national, continental and planetary - it is the condition of survival and increase living standards for the population involved;

- Reconsidering the primary ecological factors is the starting point of an effective ecological approach. Air, water, soil, flora, fauna, climate etc. must to be treated starting from their specificity and multiple interdependences between them. This is the only way to ensure the preservation and simultaneously, their valorisation in the interest of social and economic development;

- Eco-knowledge is a relatively new category of strategic knowledge, which refers to the environment and should be the focus of all entities. Eco-knowledge with eco-standards are essential landmarks in designing and implementing solutions that to generate both economic - social performances and environmental performances.

d) The educational dimension is the latest outlined, it reflecting the importance and the growing impact of ensuring human resources that possess relevant knowledge on social economic entities, taking into consideration three main plans:

- To be performing, the knowledge based 
entities is necessary to have some knowledge in terms of specific objectives, both at the level of knowledge specialists and the level of the organization as a whole. Essential is to ensure relevant knowledge to satisfy specific needs of the entity and communities based on knowledge within it.

- Education and training, through which ensure knowledge assimilation by the population at the level of the current requirements, should be treated as essential factors of development, as productive branches with a high social and economic impact. Continuing education and training must ensure an increasingly more volume and constantly changing of knowledge and their assimilation by population at the level of the entire society.

- Transformation of economic social entities into learning organizations is a systemic way through ensures to the staff of each entity the knowledge it needs in a pragmatic vision. Unlike previous approached plan, learning organization limited only to entity and is focused on certain categories of knowledge that meet the needs and requirements of the organization;

Between the four dimensions is closely interdependent relationships based on complementarity and subordination to achieve the fundamental objectives of each entity. Plenary manifestation of the four dimensions is the determinant element of obtaining sustainability and sustainable performances in any country, at the level of any social and economic system.

\section{Conclusions}

Quadrangle highlights the four dimensions of efficiency and effectiveness of economic social entities based on knowledge economic, social, environmental and educational. In our opinion this quadrilateral synthesizes in systemic way the essential elements of economic and social utility of knowledge based organizations and management. The four dimensions on which is structured the model represents axes that must be considered by managers and stakeholders from level of all economic and social entities - micro, meso, macro and international - to decide and act in order to capitalize the huge potential that knowledge have and to generate an accelerated and performant development of all economic and social systems.

In conclusion, the performances of organizations based on knowledge, must be approached systemically, treating equally the economic, social, environmental, educational aspects, internal and of main stakeholders, qualitative and quantitative, quantifiable and unquantifiable, on long, medium and short term, considering the special nature, the essential role and multiple functions and impacts of knowledge.

\section{References}

[1] Charles Barthold, Corporate social responsibility, collaboration and depoliticisation, Business Ethics: A European Review, Vol. 22, No 4, pp. 393-403, 2013.

[2] Constantin Brătianu, Organizational Knowledge Dynamics: Managing Knowledge Creation, Acquisition, Sharing, and Transformation, Hershey, IGI Global, 2015.

[3] Frederic Laloux, The future of management is teal, Strategy + Business, No 3, pp. 6982, 2015.

[4] Mian Ajmal, Petri Helo, Tauno Kekäle, Critical factors for knowledge management in project business, Journal of Knowledge Management, Vol. 14 No 1, pp.156-168, 2010.

[5] Ovidiu Nicolescu and Ciprian Nicolescu, Organizația și managementul bazate pe cunoștințe, Bucharest, ProUniversitaria, 2011. 
[6] Peter Zollinger, Sustainable Management? Don't Bother! in Jan-Dirk SeilerHausmann, Christa Liedtke, Ernst U von Weizsäcker, Eco-Efficency and Beyond: Towards the Sustainable Enterprise, Sheffield, Greenleaf Publishing, 2004.

[7] Promod Barta and Vijai Barta, Management Thoughts, Full Circle Publishing, 2004.

[8] Sabyasachi Sinha, Aspire to build an ethical and sustainable organization? Renew thyself, Strategic Direction, Vol. 33, No 1, pp. 7-9, 2016.

[9] Shu-Hsien Liaoa, Wen-Jung Changb, Chi-Chuan Wub, An integrated model for learning organization with strategic view: Benchmarking in the knowledge-intensive industry, Expert Systems with Applications, Vol. 37, No. 5, pp. 3792-3798, 2010.

[10] Thomas Hutzschenreuter and Julian Horstkotte, Knowledge transfer to partners: a firm level perspective, Journal of Knowledge Management, Vol. 14 No. 3, pp. 428-448, 2010

[11] Zahid Yousaf, Abdul Majid, Strategic performance through inter-firm networks: Strategic alignment and moderating role of environmental dynamism, World Journal of Entrepreneurship, Management and Sustainable Development, Vol. 12, No. 4, pp. 282$298,2016$. 